\title{
The Language of Disappointment: On the Language Analysis of Feeling Words ${ }^{1}$
}

\author{
Bas Levering \\ University of Utrecht
}

This is an introduction to a specific form of ordinary language analysis that tries to bridge the gap between phenomenological analysis on the one hand and conceptual analysis on the other. It shows that it is possible to analyze a feeling word and at the same time analyze the lived experience indicated by that word.

Before starting the analysis of the term disappointment, something must be said about some basic philosophical problems connected with the use of the method of conceptual analysis. These questions are not be pushed too far, and pragmatic answers are formulated. If the reader is not interested in these kinds of questions or if he or she wishes simply to start the analysis, it is possible to skip the first section on language and to start with the second section, a conceptual analysis of disappointment.

\section{Reality and Social Reality}

It is intended that conceptual analysis be presented here as a method of analyzing terms of experience, and accordingly, philosophical problems concerning the relation between language and reality are not of main interest. However, the subject cannot be completely ignored. Usually we try to avoid statements on the status of the concepts being analyzed. Having chosen the point of view of the so-called methodological nominalism, statements on the status of concepts are renounced. In ontological nominalism, statements on the status of concepts are made in the sense that the existence of extralinguistic concepts is denied. In methodological nominalism, it is clear that there are approaches with ontological pretensions, but analyses of that sort are generally concluded to be nothing more than clarifications of linguistic use.

From a philosophical point of view there are and were enough alternatives. Methodological nominalism in all its remarkable attraction goes straight back to Wittgenstein, taking into account that, for him, it is essential that language be connected to nonlinguistic activities (Dummett, 1978, p. 435 and pp. 445, 446). Austin (1976), however, spoke differently at the time about these issues. It may be significant that Austin thought ordinary language philosophy or linguistic philosophy was characterized better by the term linguistic phenomenology. Accord-

Phenomenology + Pedagogy Volume 101992 
ing to Austin, an examination of what should be said or which words should be used in a particular situation is not an examination merely of words, but also of the realities the words are used to discuss. Therefore, in this case, we still talk about a reality outside language. According to Austin, the sharpened awareness of words is used to sharpen the perception of the phenomenon, though not as the final arbiter of the phenomenon (p. 182). In conceptual analysis, everyday language has the last word (if there is such a thing) as seldom as does everyday experience in phenomenological analysis; rather it is the start. In language, experience passed down from generation to generation is stored. According to Austin, this knowledge is especially intended for solving practical problems of everyday life and is not directed at solving metaphysical problems (cf. Austin, 1976, p. 184). I stated earlier that our purpose is not to find the solution to philosophical problems, but, on the contrary, to analyze everyday life. Therefore, we need not get carried away with this philosophical debate, but we can show that, in this version of conceptual analysis, there is more between language and reality than methodological nominalism would have us believe. We restrict ourselves to show that the conventional usage of a word forms too narrow a basis to bear the concept we apparently have of reality.

In the first place, starting from conventions can lead to the misunderstanding that our concept could not exceed rules of linguistic use. A comparison of one concept in different languages shows the untenability of this proposition. In the second place, starting from conventions can lead to the misunderstanding that concepts can be changed easily by changing the rules of linguistic use. A comparison of different examples shows that this is far from being the case in all circumstances. Again, methodological nominalism does not pronounce on these issues. Does it not say implicitly that it finds them unimportant?

That our concept exceeds conventions in terms of rules of linguistic use can be shown easily by means of the following example. There are many things for which one language has a word where another does not. Does this mean that the absence of the word reveals the absence of the thing? If a Dutch translator were to translate the German book Wesen und Formen der Sympathie (Essence and forms of sympathy) by Scheler (1974) he would discover that in Dutch there is no equivalent for Mitfreude (a construction of a literal equivalent in English would be something like a combination of sympathy or compassion and joy, "comjoy"). Dutch uses medelijden as German uses Mitleid (English: compassion), but medevreugde is not a Dutch word, just as "comjoy" is not an English word. Does this mean that the Dutch lack the corresponding feeling? Of course not. It could be decided by agreement to introduce the word into the language, although as yet it may sound both strange and ugly. That this is not the case may emerge from an analysis of the English word sympathy. English also lacks an 
equivalent for Mitfreude. In English this appears to originate in the meaning generally attributed to the concept of sympathy. "The circumstances about which we sympathize with others are always unpleasant and involve some kind of suffering: it would sound odd to say one sympathized with a person who was enjoying himself or having a good time" (Mercer, 1972, p. 5). A Dutch analyst would never have made such a restriction. Despite the fact that the Dutch do not know such a word as medevreugde (comjoy), they do not restrict the meaning of sympathie or meevoelen to unpleasant circumstances and specific forms of suffering. However, does the analysis of the English term really imply that English-speaking people are not capable of sympathizing with the joyful? And if there is conscious sympathizing with the joyful, one possesses the concept, despite the lack of the word.

Also, the possible misconception that linguistic conventions are arbitrary can be easily refuted by means of some examples. It is true that some words go back to mere agreement. The word meter can be easily disconnected from the conventional reference. When the word was introduced it could as well have been connected with another length. This is a matter of a coincidental relation between name and thing, nominalism in due form. It is possible to think that the agreements on the meaning of the concept meter could be changed and meter from then on would be used to refer to what until now has been called half a meter. However, it may be difficult to bear the thought of this happening.

Even so, there are words less easily connected with arbitrary conventions. A good example can be found in Mercer's (1972) analysis of the concept sympathy. As one of the necessary conditions for speaking of sympathy, Mercer points out that one is altruistically involved in another's welfare (p. 19).

There is convention in the sense that we use the word this way, but its use is not arbitrary in the sense that we could change that use. Someone can be concerned for the welfare of others out of self-interest, but this is not called sympathy. In such a case, one does not "really" sympathize, because that includes feeling compassion with someone else's fate and excludes selfishness. It seems as if we have a grip on psychological processes themselves, because it is imaginable that someone initially exploits someone else's fate, but pushes away all selfishness once real compassion breaks through. So the meaning of the word sympathy or compassion is conventional, in the sense that the term is just used that way, but not arbitrarily. Apparently we do not need to know anything on the basis of socially defined concepts in order to discover that in one case they are as malleable as wax and in the other as tough as leather. By means of conceptual analysis we can 
discover whether conventions are arbitrary or not, but we cannot explain why.

An example of a concept that is even more difficult to connect with arbitrary conventions is the distinction between colors. This means that something can be of only one color at one moment. There is no doubt that this is a convention in the sense that we do indeed speak about colors that way. However, the distinction between colors is certainly anything but an arbitrary fact; furthermore, it is inconceivable that someone would want to assert that there can be two colors in the same place at the same time. We cannot change anything about colors behaving the way they have been described, but rather that this behavior is a property of colors.

On the other hand, we can say that the distinction between colors is presumed in the way we teach colors to children. Sometimes children try to play a trick on us, and they will say: "This is yellow, right?" and name the color wrongly on purpose. One may reply, for instance: "That can't be, that's red!" In normal linguistic use, colors are defined ostensively. One teaches children colors by pointing to them: "This is yellow" and "This is red," and that implies "Here can't be another color," otherwise "This is yellow" would not mean anything. The distinction between colors can be considered a convention, but it is not an arbitrary convention. It is even difficult to take it as socially defined.

Conceptual analysis is used here as a method of obtaining access to social reality itself. This is the reason why we do not talk too much about philosophical problems with regard to the relation between language and reality. In itself, it is also interesting, for example, to inquire after social phenomena. In this way the effect of changeability of conventions can be elucidated. However, as has been shown, the question of whether we have to make do with arbitrary or less arbitrary conventions can be dealt with effectively at the level of language. Ontological questions do not need to be asked to obtain access to social reality: it shows itself in language.

\section{General Concepts and Thick Concepts}

The use of conceptual analysis in pedagogy is especially known through analyses of central general concepts such as behavior, act, freedom, pedagogical relation, educational goal, knowledge, learning, and so forth. In this area the method has indeed proved itself. However, these general concepts are less effective in gaining access to social reality. Too often they lead to disputes about recurring issues. In other cases, these analyses give insight into the structure of science itself, before it becomes clear that these central concepts are defined differently in the different sciences. They inform us about scientific language rather than about everyday experience, and in so doing neglect the original know- 
ing that makes everyday language as interesting as it is. So much scientific terminology has crept into everyday language that it has been radically changed. Nowadays a person thought to talk too much or to take into account too little the opinions of others when making decisions is called an extrovert or authoritarian; in this way, classifications have taken the place of requests to do things differently.

Everyday language has been enriched by words like unconscious, sublimation, and repression, with specific psychological meanings. This study is not ashamed to be seeking original knowing. A concept like labor has undergone so much scientific work concerning its definition that it is difficult to discover any original meaning for it. As a result, analyzing words like deceiving, promising, courage, shyness, forgetting, and jealousy is preferred. These thick concepts, as Williams (1985, p. 129) calls them, seem to express a unity of fact and norm. It is just these moral connotations, polished off in most scientific analyses that we want to know, because apparently it is not just about "arbitrary" descriptions, but also about compulsory prescriptions. In this respect, it is significant that Vendler $(1971$, p. 258), in the case of rules, talks about prescriptive descriptions, and at the same time makes a pragmatic pronouncement on the status of concepts. In another connection, it is significant that phenomenologists talk about thick descriptions (Beekman, 1982, p. 19), for, in my opinion, the similarity of intention surpasses a coincidental similar adjective.

\section{The Richness of Language and the Poverty of Linguistic Analysis}

I am prepared to recognize that my conceptual analysis provides few results from the richness of language on first sight. It is known that some novels offer considerably more information about reality than do many social science reports. It goes without saying that some poems express certain matters more aptly and are more powerful than social science. It cannot be stressed enough that the lines between art and science are more vague than some scientists would like us to believe. There are magazines that really function as a meeting point of art and science. But science itself is never poetry. Science always wants argument. Because of the mere evocative force of poetry, it cannot implement the argumentative function. Science can explain how a poem works, how poetry can excite understanding, but this seems to be more the task of literature than of social science. And if it is the task of the social scientist to explain how understanding poetry works, he or she is obliged to consult the science of literature or to reject the vision of the latter with argumentation. But perhaps I do myself and conceptual analysis an injustice by praising poetry like this while pleading for professional analysis. An example follows.

Freedom is a central philosophical-anthropological concept that has undergone many attempts to define it more closely. One of the modern 
definitions of freedom reads: "He or she could have done otherwise." It is well known that to the analyst such a definition is still much too rough, because some terms should be defined more closely, but we will leave that aside.

Through the ages freedom has also been a subject for poets. As late as 1984, the Dutch 1960s protest-singer Armand wrote: "Freedom is a Mercedes refueled." It is not clear that this is a result of poetic genius, but still it is presented as an example of what poems can do.

The examples are meant to clarify the evocative aspect of the poem as well as the argumentative character of conceptual analysis. The experience the poem wants to evoke will be recognized by few people. "He or she could have done otherwise" should be found in any freedom, but does not yield immediate recognition and can be found only after careful investigation.

The difference is not as great as it seemed at first glance. If only the evocative aspect of "Freedom is a Mercedes refueled" made the sentence, it would fall on deaf ears for many people. Many people do not like Mercedes. Apparently such a sentence does not work by evoking recognition. It works as a successful appeal to imagination, because despite the fact that many people would only feel embarrassed in a car of that model, the sentence is capable of putting into words the concept freedom because just as many people can imagine experiencing freedom that way. An analysis of the efforts imagination has to make in such a case gives insight into the characteristics of a concept. Such an analysis seems rather cold, but saying that it does not make sense to explain a joke because the fun is lost is different than denying science the right and opportunity to explicate a concept. Also, in "Freedom is a Mercedes refueled," "He could have done otherwise" is an important element. This does not make the concept shrink, but rather grow.

The scientist does not write poetry. Heidegger (1971) was not writing poetry when analyzing Wesen und Dichtung in Hölderlin, though his language is too dramatic for analytical ears. By explaining what is involved in the relationship between language and Dichtung (broader than poetry), with reference to five Hölderlin quotations, he makes clear what language does and is (pp. 33-48). Uninspired science is indigestible, but if science tries to be artistic, it results in kitsch most of the time. If the argumentative element is lacking, it is not science. This is exactly what Peters (1973) means when he characterizes the method of his predecessor Reid in the latter's book Philosophy and Education by saying: "He raises most of these issues in a very specific way. But he tends to paint with his pen rather than to lay out systematic arguments" (p. 271). 
By means of another example, let us try to show how poor the results of meaning-as-use analyses can be. Wittgenstein says this about love: "Love is not a feeling. Love is, put to the test, pain not. One does not say: "That was not true pain, or it would not have gone off so quickly" (Wittgenstein, 1967, p. 504).

Any poet will object to heavy artillery like this. For centuries the feeling has been sung, and now all of a sudden the philosopher says love is not a feeling. But let us see first what Wittgenstein does say about love. A characteristic of love is that it does not disappear just like that. We would almost say a characteristic of love is faithfulness.

This link between love and faithfulness goes beyond the range of simple doggerel and is put into words in an even more down-to-earth way: a characteristic of love is that it has a certain duration. And indeed we use the term love that way. After all, some people conclude when people split up after having lived together for many years that they do this because they never really loved each other. (By saying this the commentators think to have a causal connection in mind, but in reality they only express a logical connection.) Therefore, it would be absurd when being stopped while leaving in the morning by the comment: "But last night you told me you loved me" to reply: "Yes, last night I did, but not any longer."

Hardly ever will such a simple conceptual analysis throw so much light on the cause of so much grief. It is of minor importance here that the wrong use of the term can have its origin both in clumsiness and in deliberate deceit.

However, saying that love is not a feeling is another story. Wittgenstein comes to this conclusion because he presents pain here as the archetype of a feeling. A substantial part of his Philosophical Investigations (1953, pp. 241-317) is dedicated to making a reasonable case for this. He claims that talking about feelings in general and pain in particular is not about inner events, or, more precisely, he claims that no pronouncements can be made about the existence of inner events. Although the writer and the poet in total abandon make the most of the confusing character of feelings of love, Wittgenstein concludes that the idea that love is a feeling is caused by linguistic confusion.

\section{To Analyze is More Than Just Establishing the Correct Use}

Every competent language user is potentially a competent conceptual analyst. In their everyday lives people are constantly demonstrating that they know much more about principles of language use than they are able to glean from dictionaries or grammar texts. It is astonishing that so many rules can be explicated that were never explicitly acquired. And even if the innumerable language rules would have been explicitly learned by individual language speakers, it would be 
unimaginable that these rules could have been of functional reproducible value. Somehow language rules are maintained by principles of use, in spite of the fact that these rules are constantly violated. And yet it is usually not difficult to determine what uses are correct and incorrect.

For effective conceptual analysis Austin (1976) recommended teamwork because so much work needs to be done. There is much less difference of opinion about the appropriate use of words than one might perhaps suspect (p. 183). However one should not suppose that intersubjective validation makes certain rules of use more correct. General consensus signifies only that others have discovered the same rule as I have, which does not make the rules more correct. We are not searching for empirical generality of use. Such a search would constitute an empirical survey where the experience of others would play a significant role. However, we are searching for correct use in a normative sense, and once such correct use is discovered it needs neither to be denied nor affirmed. Of course this does not mean that conceptual analysts do not make mistakes or that the norms are unalterable.

The usefulness of teamwork is not situated in the sense that two are more knowledgeable than one. It may sound superfluous, but the fact is that every competent language user already knows everything and seldom is in doubt when asked about some rule of correct use. Rather, the usefulness of teamwork is situated in the sense that two can ask more questions than one. The important concern is with the posing of creative questions. Although practice plays some role here and although talent should not be underestimated, every new question can be of relevance.

If there is still a difference of opinion, then we would do well to pause. It may appear trivial to say in such a case that the difference of opinion points at some important issue in the analysis of a concept. The vigor with which people express their differences certainly seems to underline that observation. Frequently the disagreement can be traced back to the ambiguities that inhere in ordinary language, and it can often be seen to correspond to some underlying philosophical issue that has defied satisfactory solution. It is sometimes, but not always, possible to contribute to the resolution of such problem through the analysis of thick concepts.

Still, it seems too simple to be true that such an uncomplicated procedure as asking questions can put us on the track of the meaning of a word. It begins invariably with "It's absurd to say." The discovery that one just does not say something in a certain way immediately shows the way to the correct use. It tells us what characteristics we do and do not attribute to the concept. Language has the first word, as Austin says. The questions we ask are a child's rather than those of a mature 
person. They express puzzlement rather than a request for precise information. The questions are asked without clearly knowing what the questions are: "They are expressing a feeling or mental uneasiness. The voice of the instinct is always right in a certain way, but has not yet learned to express itself exactly." According to Wittgenstein, we certainly do not discover new facts this way, but we know all the facts we have to know from the beginning (cf. Lee, 1980, p. 22; Moore, 1978, p. $45)$. Here it is not about raking up the a priori problem once again. It is about assessing that this language is very much the same as that of some phenomenologists who say that the trick is making prereflective knowing reflective. The difference of accent can be found in the fact that some speak of prereflective experience instead of prereflective knowing. We obtain knowledge of the rules of language use by means of examples. It is about assessing that we cannot deal with the meaning of a word by explicating the rules of linguistic use. One can make a fuss about those rules; they exist immediately; they are given with our so-called linguistic intuitions. Rather, conceptual analysis is about the story we have as a result of the rules of language use made explicit. It is about the answers to the childlike $w h y$. And too often those answers are difficult to put into words, if they can be put into words at all.

\section{"Disappointment"}

For sale due to disappointment: wedding dress.

I'd rather have spared you the disappointment.

You could see the disappointment on her face.

Despite all efforts the event ended in a big disappointment.

The chairman expressed his disappointment about what had happened.

Most citizens are disappointed by politics.

The father was bitterly disappointed with his son.

I think the latest book by this author is disappointing.

The first day at the new school was a disappointing experience.

To my regret, I have to disappoint you.

The fact that good results failed to appear disappointed the management.

Time and again I am disappointed that you don't keep engagements.

\section{Tentative Description}

It does not cause too much trouble to give a tentative description of disappointment. By the word disappointment we refer to the unpleasant feeling that arises when certain expectations are not realized. This immediately evokes the question of whether disappointment can occur without expectation, or more precisely whether expectation is indeed a prerequisite for the use of the term disappointment. In fact many unpleasant feelings have nothing to do with expectations, but they are not called disappointment. The pain after falling off a bicycle or the shock of a snowball in your face are not called disappointments. They come unexpectedly. This does not mean this sort of event was thought to be impossible, but that it was not expected that the event 
would happen at the moment it occurred. This is why people upset by someone's death say that such a thing always happens unexpectedly, even though everyone knew it could happen at any minute. An emphatically unexpected event that nevertheless takes place may cause disappointment. For example, this is evident in the attitude of proponents of nuclear energy convinced of the safety of nuclear power stations and their disappointment about the Chernobyl disaster.

The question is whether expectation is a sufficient condition for disappointment. Do unfulfilled expectations by definition lead to disappointment? When a negative expectation is nourished, that is, when I expect something I would rather not see happen, and in fact it does not happen, then I feel relief instead of disappointment. The question is whether relief can be seen as the opposite of disappointment in the sense that the former is about a cheerful feeling and the latter about an unpleasant one. If I pass an exam about which I have had the most anxious expectations, I am first of all rather relieved, then glad. This means that when talking about disappointments there are always desired expectations involved.

It should be added that when talking about disappointment it is about an expectation not coming true that is of "sufficient importance." It may seem worth considering that this "sufficient importance" is enclosed in the term "desired expectation," but desired in the sense of not-undesired is far too weak for this. That a certain importance is indeed required before talking about disappointment can be shown by the fact that when dropping a cup one cannot say one is disappointed. Rather, in such a case, we say "Too bad!" Missing a bus, stepping in a puddle, and losing a 10-dollar bill are all too unimportant to feel disappointed. What counts as being of sufficient importance is measured by a general standard, but is nevertheless contextual. We will be disappointed if we dropped a very special cup we were attached to, or if a very special bus trip is cancelled, or if we lose all our money.

All this makes the tentative description a few steps more specific. We use the term disappointment to indicate the unpleasant feeling that occurs when desired expectations of sufficient importance do not come true.

\section{Is Disappointment a Feeling?}

It is possible to say "I feel disappointed." Is this an expression of a feeling different than that expressed when saying "I am disappointed"? This seems to be the case. It is not even absurd to say "I feel disappointed, but I am not" or "I am not disappointed, but I feel so." The difference seems to concentrate on the question of whether or not one feels justifiably disappointed. This only plays a role in cases when both forms are used in combination or confrontation. When the question of 
whether one feels justifiably disappointed is not at stake, both forms can be used interchangeably. However, this question can also be asked then. When someone says, "I'm disappointed," we can ask, "Isn't it that you only feel disappointed?" And when somebody says "I feel disappointed," one can ask "but are you?"

Now that disappointment has been characterized especially as an emotional term, one can wonder to what extent disappointment is linked with other emotional terms. Subsequent to an expectation not coming true, many emotions seem to be at issue. Only too often, elements of grief, anger, rage, despair, powerlessness, and gloominess play a role. Still, these words suggest an atmosphere that, in a further analysis of these terms, would provide evidence of sharp differentiations between these emotions and disappointment.

Feelings of grief and anger, for instance, seem to be easier to recognize on the outside than disappointment. However, one must be careful here. When, pointing at a picture, one says to someone: "How angry are you looking here?" the individual may reply: "I'm not looking angry at all, I'm just thinking." Sometimes it is said that "one could read the disappointment on his face," or "she could not hide her disappointment," but it is only possible to say that if we know the context. Only knowledge of the circumstances, knowing that an expectation not come true is at issue, can cause a "sad" face to be interpreted as glum, crestfallen, and thus disappointed. It is impossible to recognize an unknown face in a picture as disappointed. Grief and anger are more likely to be recognized apart from the context. But one should not make the mistake of thinking that disappointment is a specific form of grief. Grief should not be taken to be a more general emotional term.

\section{"I am disappointed" as Speech Act}

It may have something to do with the difficult readability of disappointment that it is commonplace to put into words one's disappointment by saying "I'm disappointed." Although in the last 10 years it has come into vogue to express different, more evident feelings as well, it is still absurd to say "I'm angry" or "I'm sad." It can be defended with young children who have not yet learned to read feelings on faces. Perhaps it is even the only way to teach them to become acquainted with our feelings. Among adults, however, it is ridiculous to bring forward one's own anger in words. Others can see it!

It may also be the case that disappointment can be used not only to draw somebody else's attention to those feelings, but with the express intention of evoking a reaction in the other person. "I am disappointed" calls the other person to account. Suppose one hears that a good, faraway friend has been in town, but failed to drop by. This can be a reason to express disappointment at the first possible opportunity. A 
number of reactions are possible on such an "I'm disappointed," depending on whether the other person thinks there is a right to be disappointed or not.

It may be the case that the other grants you the right to be disappointed, but that there were circumstances that made it impossible for him to visit you. "Too busy," "too little time," there are enough valid excuses to think of, but perhaps you would rather be informed earlier. It may also be the case that the other grants the right to be disappointed, but realized only later that there would be disappointment. "I did not know this would be so important to you." Such a reaction implies the promise to act otherwise next time.

It may be the case that the other individual denies your right to be disappointed. She or he will explain that one should not count on anything in such a situation, that there is a good chance she or he will not drop by on a subsequent visit to town either, and that it should be understood that she or he has other things on her or his mind too. This can go together with the recognition of the feeling of disappointment: "I'm sorry you feel disappointed, but that's how it is." The other person feels sympathy, but does not accept responsibility for the disappointment. The question is, of course, whether this reaction will be satisfactory. A possible continuation of not recognizing the right to disappointment is indignation because the other person does not recognize your values.

The disappointment will certainly not always be expressed in the way discussed above, because the speech act "I am disappointed" will be stated in only few cases in order to evoke this sort of reaction. This does not mean that this explicit phrasing could not offer an adequate description of the process of interaction. Sometimes the speech act is deliberately omitted. It would not be desirable for a fuss to be made in all cases. Sometimes the speech act is omitted because the other position is understood, and the arguments are known. In this case, the speech act discussion has taken place in the disappointed person's head.

In some cases, it may be that the need to state the speech act creates disappointment in itself. In a way, this means being disappointed twice. The other person should have recognized the disappointment or should have understood that there would be disappointment, and the need to express the disappointment is in itself disappointing. The other person is also held responsible for this emotion. Often, however, disappointment will be obvious immediately and it is not necessary to hint at it. 
It may be that disappointment is not expressed in order to avoid the rude awakening of meeting with a refusal, thus being disappointed three times. In these instances, the emotion is kept to oneself.

The impression may have been created that the structure of interaction that has just been discovered, by means of taking "I am disappointed" as a speech act, is reserved for hypersensitive, perhaps even somehow therapeuticized social environments. There are big cultural differences in the extent to which one is allowed to worry or make a fuss about that sort of question. It is quite conceivable that in some cultures a person would make an absolute fool of himself or herself when indicating that he or she feels offended because someone failed to keep an appointment that was not made explicitly, as was brought forward in the example above. Maybe friendship has another meaning in such a culture. It is also conceivable that there are matters about which one does not make a fuss. Besides, certainly in some cultures the accompanying conflicts are dealt with in another way than indicated here, or the emotional conflicts mentioned do not even exist.

Therefore, a disappointment is more than a perception; there is always an orientation to a general standard at stake. Initially, it may have looked as though the question of whether disappointment is about an expectation of sufficient importance not coming true could be determined by individual values, but a closer look reveals that feelings are always under a general standard.

Whether a cup means so much to me that the result would be disappointment if it broke seems to be an individual matter, but the question of whether it is permissible to be disappointed by something like that is a general question. More precisely, it is about general and individual standards. Somebody who behaves like a disappointed child is disappointed with things about which adults should not be disappointed. It can also be true that this person does not deal with his or her disappointment in an adult way, but this amounts to the same thing.

In claiming the right to disappointment, phrasings other than the speech act "I am disappointed" analyzed above are used as well. In such a case we often hear a phrase not asking for comment, but claiming objectivity: "This is disappointing."

\section{Who is Responsible for the Disappointment?}

The treatment of "I am disappointed" as a speech act has as an implicit starting point the premise that the other can be called to account. Apart from the question of whether in fact the other lets himself or herself be called to account, it is important in this respect to ask whether it is possible to disappoint someone deliberately. Of course it is only possible to disappoint someone deliberately if one is acquainted with the other person's expectations. However, even if this is the case, 
and thus one knows one will disappoint the other, it is odd to say that in such a case one deliberately disappoints the other, because disappointment is rather a side effect of the action than the central assumed purpose. In this sense, disappointment is in some way inevitable. It looks as if, when one wants to hurt someone, and chooses the laborious way of disappointing, one would not say "Let's have a good time disappointing that person," because in such a case hurting the other is the act, and the way in which the hurt is caused is of minor importance. However, if it is concluded that it is not possible to disappoint someone deliberately, can it also be concluded that it is a characteristic of disappointing that it occurs by accident? It has already been found that this is true when the other person's expectations are not known. However, when one is acquainted with the other person's expectations, it is not correct to say one disappoints the other by accident. In such a case, one does not disappoint on purpose, but about the unintended effects of inevitable acts, it is meaningful to say: "I am sorry I have to disappoint you."

In order to be able to answer the question of who is responsible for the disappointment, it is also necessary to ask who is responsible for the expectation. After all, there can also be a question of disappointment simply because the victim sets his or her expectations too high. In order to be able to determine when we can speak of expectations set too high, we have to become acquainted with the general, culturally determined standard. On examination, it appears that there are not only big intercultural differences between reasonable expectations in life, but also that within cultures there are inexplicable and unclear questions regarding this issue. About love, Wittgenstein teaches us that the statement "I love you" is not a report of an inner circumstance, but a speech act that means, in the appropriate circumstances, "I always want to stay with you." In such a case it is clear that the speaker is responsible for the expectations. Although it does not concern us here, it is unfortunate that it is unclear what should be understood as the appropriate circumstances, with the result that often it remains unclear whether it is the speaker who evoked the expectations or the listener who undeservedly got things into his or her head. The theoretical solution for this sort of problem is, of course, that it is easy to create clarity where none exists, but according to others, this sort of situation exists only in a practical sense because of the lack of clarity.

Is it possible to be disappointed in yourself the way you can be disappointed in someone else? It is possible to be disappointed by events (about is more vague) or in people. The disappointment in people is not purely bound to persons. It is also possible to be disappointed in politics or in the company or in humanity. In these cases, the disappointment is directed at personified authorities that do not always correspond to actual persons. An important question accompanying this sort of disap- 
pointment is the question of whether the object of disappointment can be called to account.

When the disappointment relates to persons, it can relate to their qualities or to their behavior. When it is related to behavior, the disappointment can be taken away by the other changing his or her behavior. However, when one is disappointed in a person's quality, there is nothing else to do but adjust the impression one has of that person. In this way, we learn through disappointments. People appear to be different from what we thought or from how they act.

Still, there are different ways to deal with this adjusted image. The adjusted image of the other can lead to adjusted expectations; in the future one will make other demands on that person. However, one may also wash one's hands of the other and have nothing to do with that individual in the future.

Can the same story be told about being disappointed in oneself? It is possible to change behavior by way of self-criticism. Disappointment can indeed be the cause for such a change. For example, people who notice that they let themselves be persuaded to do things they do not want to do may be inspired to change their ways. Many psychologists do not give much credence to the self-correcting ability of people, but that is a different question. Here, the matter for discussion is the question of being disappointed in one's own behavior, to which one can link the wish to change that behavior. One can also be disappointed in one's own qualities. However, it is not possible to turn away from oneself as one could turn away from another person. Even so, it is possible that, through disappointments, a better insight into one's own abilities can be obtained. One's own abilities can of course be discovered when certain acts go well, although it had previously been feared that they could not be done. For the rest, the way through disappointments seems to be the only way to learn what one's possibilities are. Here, too, expectations can be adjusted on the basis of a changed image.

There is a case for saying that one knows one's expectations better than someone else knows them, because people only too often keep their expectations to themselves. However, does one by definition know one's own capacities better than someone else knows them? No: I know my own capacities the way someone else knows them. The difference between being disappointed in oneself and being disappointed in someone else lies in the fact that being disappointed in oneself will be experienced more seriously (in matters of comparable importance), because one holds oneself more or less responsible for one's own opportunities. If one is disappointed in oneself and puts the causes outside oneself, we say instead that one is disappointed in life. However, some people seem to be pursued by misfortune, but unjustly suspect the reasons for a life 
full of misfortune to be within themselves. In general, the most destructive sorts of disappointment are those where one repeatedly proves to be incapable of gearing expectations and opportunities to one another, and then feels responsibility for the ensuing disappointment.

We have not chosen the concept of disappointment here for its pedagogical relevance, but for its supposedly rich prospects for analysis. Still, it is possible now to say something about differences in the meaning of disappointments for adults on the one hand and children on the other. In the case of very young children, it seems inappropriate to talk about disappointments. This is only possible from the moment in development at which expectations are at stake. When parents are disappointed in children, the disappointment generally relates to expectations for the future that have not materialized. When parents are disappointed in their children, they seem to think the responsibility lies within themselves. Children can also be disappointed in characteristics of their parents. If, for example, the disappointment refers to an "unsuccessful education," they will not place the responsibility within themselves. Disappointed children reproach their parents for lack of support or negligence. The remarks on the responsibility for the disappointment here, however, do not pertain to a particular feature of the concept, but rather to the empirical assumptions that go beyond the limits of conceptual analysis. So there are many interesting questions to be asked. Children seem to be disappointed more often than adults, but the grief seems to be of shorter duration. Also, in order to know exactly what disappoints children, empirical research is indispensable.

Is knowledge of the term necessary to have the feeling? The mere question can evoke a storm of indignation. A feeling, that is, something one has with a name for it, is of minor importance. Still, it must be realized that it is difficult to describe the feeling as such. It is difficult to get beyond rough, atmospheric similarities to grief, anger, powerlessness, or to get beyond an indication, like unpleasant or horrible. So, the question remains of whether disappointment can be felt without the realization that there is an expectation that has failed to come true.

Without too much reserve, one can agree with the Wittgenstein's description of learning feeling. How else would one learn the feeling of disappointment? It is the parents who now, in the appropriate circumstances, ask the dismayed child: "Are you disappointed?" And the child will not protest, but take advantage of it.

However silly it may sound, it is tempting to assume that feelings only exist through language. In the first of his Anton Wachter novels, Vestdijk (1983) describes how the maid Janke expresses her contempt about the "courtship" of the seven-year-old Anton of Annie Vermeer. Anton does not hear exactly what she says. It sound like "well" or "right" (the rebuke misses the mark) - "but Anton, in whose vocabulary 
of feelings sarcasm did not yet exist, had already gone away" (pp. 53-54, italics added).

Perhaps it is better to say that subtlety in emotional life is brought about by language, for it is odd to say that we know hunger only if we have a word for it. It may be in order to consult phenomenologists here and follow a phrase by Merleau-Ponty who says that the feeling is completed by the word. It is not simply sensation plus meaning, for the sensation as such is meaningless. However, the child need not, as linguistic analysts say in such a case, be able to list the defining characteristics of disappointment in order to know what disappointment is.

Not only with children do feelings become concepts because specific meanings are attached to them; with adults something like this is also imaginable. After all, it is possible to have a vague, unhappy feeling, while one is unable to discover what this feeling consists in or how it came about. In such a case, it may occur that someone knowing the individual and the story (the context) says: "Well, of course, you're just disappointed," and by this solves "all problems." In such a case, of course, the term is recognized as fitting the feeling. Yet the term also makes the feeling. From one moment to the other, it can become clear that the unpleasant feeling has everything to do with unfulfilled hopes, for instance.

The incomplete feeling discussed above should not be confused with what is generally denoted by the term indefinable feeling. An indefinable feeling is a feeling in itself, like disappointment or grief and is suitable for analysis in the way we are analyzing disappointment. If one says one has an indefinable feeling, there can be no doubt that one really has that feeling. Doubt only arises when one no longer has the intersubjective meaning clearly in mind. "Do you feel pain when I do this?" asked the doctor. "Well, pain, pain ...?" said the patient, who had walked with it for a couple of days, "I don't know whether this can be called pain." He did not feel well, and about that he had no doubt at all (cf. Canfield, 1975, pp. 142-143).

\section{Synonyms, Xenonyms, and Etymology}

Consulting dictionaries yields far less than our analysis until now. It does become clear that expectation indeed occupies a central position in the concept of disappointment. Regarding disappointment, two aspects are mentioned: the fact (the occurrence) that somehow one is deceived in one's expectations, and the situation (the feeling) of being deceived in one's expectations. To disappoint is characterized as a transitive verb-keeping someone from or not allowing someone to experience what he or she expected-but the question of purpose is not asked. In the dictionary it also says that one can be disappointed in one's feelings 
or expectations, but it does not seem to be a separate issue, because, after all, expectations and feelings are at stake in every disappointment.

(Dutch) dictionaries do not mention synonyms for disappointment. This does not mean that there are no words that resemble disappointment, such as bad luck, trouble, misfortune, or disillusionment, but in principle each one of them asks for an accurate analysis in order to denote the exact difference from disappointment.

In the everyday use of words, one is too often inclined to weigh words and to arrange them from serious to less serious. That is an everyday language problem - a problem that has a function, by the way-that has not failed to work in a certain part of social science terminology. Only too often people talk about "a bit of a relationship" or "some confidence." This usage does not agree with the basic assumptions of conceptual analysis. This method assumes that a concept is used correctly if the body of defining characteristics is at stake. If prerequisites for relationship or confidence are lacking, one should not talk about a bit of confidence or a portion of a relationship, because relationship or confidence are out of the question. This does not mean that one could not speak meaningfully about a good relationship or about much confidence, but in this case a subtle distinction in one of the defining characteristics is at stake.

At first glance, it seems as if bad luck is used when an expectation of insufficient importance is at stake and disappointment, for that reason, cannot be spoken of, as was discovered in the tentative description. Is bad luck what is used when one is a bit disappointed? No, the difference between bad luck and disappointment does not only have to do with the seriousness of the event, but also with the question of whether it is an event for which one can or cannot be held responsible. By definition, one is not responsible for bad luck, so the use of the expression in a certain situation can evoke the following remark: "You call that bad luck? I just call it stupid!" However, it is absurd to talk about bad luck in cases of serious adversity, for example, the sudden death of a friend. A death for which one cannot be held responsible is therefore complicated.

Taking a cursory look at the concepts bad luck, trouble, and misfortune, it seems that these words look at the event in a more neutral way. In disappointment there is more at stake than being unlucky. There is an element of discouragement in it, of loss or of belief and hope: this is lacking in words associated with the meaning of disappointment.

Disillusionment seems to be about a serious form of disappointment. However, it is clear that it is not just about an expectation not come true, particularly when it was realized that the result could be different 
from what was wished for and expected. A disillusionment shows that the world is quite different from what had been thought or believed. In disillusionment there is something like an awakening from a glow, a spell being broken, a disenchantment that brings one down to earth. So disillusionment is not just a serious form of disappointment, although it cannot be denied that the former is more serious than the latter, but rather in disillusionment the expectation has much more the form of a comprehensive confidence, an illusion, or sometimes even delusion.

A comparison with related concepts in other languages brings some unexpected modifications. Disappointment (Dutch: teleurstelling) has been linked with an unpleasant feeling or experience. In Dutch, one can be agreeably surprised, as in a case of an unexpected meeting with someone dear who has not been seen for years. In such a case, "a little luck" is not something that one would say. "A little luck" or "a bit of fortune" refers more to the event than to the accompanying feeling.

In French the deliberate aspect of disappointing is more stressed than was seen earlier: Déception, désappointer quelqu'un, tromper les espérances de quelqu'un. The element of deliberation can also be found in the German Täuschung, but this also means just cheating or deceiving. Enttäuschung means, apart from disappointment, also disillusionment and disenchantment, concepts linked to disappointment earlier.

In 16th-century Dutch, the deliberation is fully present in te löre, stellen, leiden, setten, which means disappointing or deceiving. The stem löre refers to the Anglo-Saxon lyre, meaning loss, but as for the deliberation, we apparently know much better than language does.

The search for the meaning of the word in other languages comes down to consulting dictionaries. Only in one's own living language, as a competent user of that language, can one analyze the meaning-as-use. Such an excursion, therefore, only has a limited significance in conceptual analysis. It can generate questions; for example, one might pursue the question of the deliberate aspect of disappointment if this had not already been discovered for ourselves.

\section{The Limits and the Openness of a Concept and of Conceptual Analysis}

The question is, of course, how long must one analyze before the analysis is completed to one's satisfaction. It is possible that more characteristics specific to the concept disappointment are to be found, although we think that the most relevant characteristics have been listed. Over time concepts will change, but in a certain historical period concepts function as modeling structures. So determining the meaning of a concept does not mean that the concept is not open to changes. The structure of the type of concepts we have been concentrating on has been characterized as open textured (Waismann, 1951). Thus the moment when one stops analyzing is arbitrary. One stops when one thinks 
there is enough, but one cannot exclude that other defining characteristics will be found (one's pride is one's own problem).

Apart from the specific characteristics that may have been overlooked, certainly some characteristics have remained unmentioned, but they are so general that they would be called trivial. (It goes without saying that the distinction between what is trivial and what is important enough is also arbitrary.) It could be said that every disappointment has consequences or that disappointment refers to the past and that it is absurd to say that one is disappointed in the future (but, by the way, not absurd to want to avoid future disappointments), and therefore consequences and past are indeed characteristics of disappointment. These characteristics are as much a part of the prereflective knowing as all other mentioned characteristics, but they are found less worthy of mention because they do not put forward any why question.

I wonder if psychological theories have much more to say about disappointment than we discovered by means of our analysis. "Disappointment is an emotional reaction to an expectation that did not come true (frustration) or turned out to be different (deception)." There is nothing new here. "Dealing with it is called bearing, characterized by the current psychosomatic condition." These seem complicated terms constructing a sort of psychological apparatus for what was known conceptually, and supposedly was known all along. Disappointment of the emotional kind is frustration.

There is of course psychological research that brings to light other than conceptual facts. If it could be brought to light that alcohol consumption correlates highly with a life full of disappointments, we would have other than conceptual knowledge (although we would not know that much more). There is also empirical research that can yield information about specific events that can disappoint certain groups of people or children. In this conceptual analysis, we are implicitly oriented toward a general norm of our times that needs specification and that can change.

Language contains all sorts of information about the meaning of disappointments in life, but moving into this requires the realization that it is beyond the limits of conceptual analysis. The ease with which people say that disappointments belong to life, that therefore children have to learn to deal with disappointments, that life without disappointments is in fact just a poor existence, suggests existential pragmatism rather than profound philosophical thought about life. The mountaineering terms in which people in everyday life talk about dealing with disappointments can tell us something about the concrete bodily experience of disappointment, but can also tell us something about the primitive psychological theory that seems to be present in everyday language. In any event, the path of life seems to go over hills and dales. High points 
and low points take turns. And if one makes an effort disappointments will be overcome. Perhaps the conceptual analysis can even contribute to the insight that in some cases we are capable of reaching the top of the hill without making too much fuss about it.

\section{Notes}

1. This introduction in the analysis of thick concepts was first published in Pedagogische Verhandelingen in 1987. It takes a stand against the anti-language-analysis attitude of my phenomenological colleagues Ton Beekman, Hans Bleeker, and Karel Mulderij from Utrecht University on the one hand, and what in my view is the logistic attitude of the conceptual analysts Ben Spiecker and Jan Steutel from the Free University of Amsterdam, on the other. Specific references to this discussion in Dutch pedagogy are not mentioned in this English version.

The analysis of the concept of disappointment is in the first place the result of two sessions dedicated to the subject in the course Conceptual Analysis and Pedagogy at the University of Utrecht in the academic year 1985-1986. The concept was chosen because of the suspected rich prospects for analysis. In order to say something about social reality, such a thick concept with many moral connotations offers the best opportunity. With regard to the individual preparation for the group session, we agreed to consult dictionaries and scientific psychological literature only at the end, and to investigate everyday language in the first place. Our aim was to formulate these questions as creatively as possible on the basis of examples. During the sessions, these questions were discussed, during which, by coincidental circumstances, we were forced to use a tape-recorder.

Looking back, this turns out to have been an essential device. Often questions coming up in discussions that cannot be answered immediately are pushed aside. It seems as if we often feel ill at ease during long collective thinking pauses and therefore pass on to another subject. In written reports it is just those questions, those that are not so obvious, that are lacking. It seems the minutes secretary has not written down these questions, because he or she did not understand them.

The analysis, as it is now on paper, has been preceded by a large amount of discussion between Marieke Eggermont and myself. Translation of an article like this is a risky enterprise. It is stated before that conceptual analysis in this form can only be carried out by competent language users. Jeanette van den Berg started in Holland, and Moira Juliebo at the University of Alberta in Edmonton helped with the draft, and the journal publication staff finished the editing job.

\section{References}

Armand. (1984). Vrijheid 2. Waar het om draait. Marlstone.

Austin, J.L. (1976a). Philosophical papers (2nd ed.). In J.O. Urmson \& G.J. Warnock (Eds.). Oxford: Oxford University Press.

Beekman, A.J. (1982). Theoretische pedagogiek: Een existentieel fenomenologische visie. In B. Spiecker (Ed.), Theoretische pedagogiek (pp. 13-24). Amsterdam: Meppel \& Boom.

Black, M. (1975). Making something happen. In S. Hook (Ed.), Determinism and freedom. New York/London: Collier Macmillan.

Canfield, J.V. (1975). "I know that I am in pain" is senseless. In K. Lehrer (Ed.), Analysis and metaphysics (pp. 129-144). Dordrecht/Boston: Reidel.

Dummett, M. (1978). Truth and other enigmas. London: Duckworth.

Heidegger, M. (1951). Erläuterungen zu Hölderlins Dichtungen. Frankfurt a.M: Klostermann.

Lee, D. (Ed.). (1980). Wittgenstein's lectures in Cambridge 1930-1932. Oxford: Blackwell. 
Mercer, P. (1972). Sympathy and ethics. Oxford: Oxford University Press.

Moore, G.E. (1967). From Wittgenstein's lectures in 1930-33. In K.T. Fann (Ed.),

Luduig Wittgenstein. The man and his philosophy (pp. 40-45). New Jersey/Sussex: Humanities/Harvester.

Peters, R.S. (Ed.). (1973). Philosophy of education. Oxford: Oxford University Press.

Scheler, M. (1974). Wesen und Formen der Sympathie. Bern: Francke Verlag.

Vendler, Z. (1971). Summary: Linguistics and the a priori. In C.Lyos (Ed.), Philosophy and linguistics. London: Macmillan.

Vestdijk, S. (1983). Sint Sebastiaan. De geschiedenis van een talent.

's-Gravenhage/Rotterdam: Hujgh \& van Ditmar.

Waismann, F. (1951). Verifiability. In A. Flew (Ed.), Logic and language (First series, pp. 117-144). Oxford: Blackwell.

William, B. (1985). Ethics and the limits of philosophy. London: Fontana.

Wittgenstein, L. (1953). Philosophische Untersuchungen / Philosophical investigations (G.E.M. Anscombe \& R. Reesh, Eds.). Oxford: Blackwell.

Wittgenstein, L.. (1967). Zettel (G.E.M. Anscombe \& G.H. von Wright, Eds.). Oxford: Blackwell. 